\title{
ARTICULACIONES ENTRE LAS INSTANCIAS DE LA PLANIFICACIÓN URBANA Y SU IMPLEMENTACIÓN EN LA CIUDAD DE BUENOS AIRES EI Plan Maestro Comuna 8. Lo legal y lo legítimo
}

\author{
Anabella Roitman \\ Especialista y Maestranda del Programa de Planificación Urbana y Regional - ProPUR \\ Investigadora en el marco del Programa Urbanismo y Ciudad + Instituto de Espacialidad Humana + Gestión \\ Urbana Contemporánea cátedra Szajnberg. \\ Universidad de Buenos Aires, Facultad de Arquitectura, Diseño y Urbanismo \\ Directora Arq. Mgster. PUR Daniela Szajnberg - Colaboradora: Luisa duggan \\ anabellaroitman@gmail.com
}

\section{RESUMEN}

Dentro de las políticas urbanísticas, la Planificación Urbana (PU) se organiza en tres instancias no lineales, que consisten en la realización de un diagnóstico territorial, la formulación de un plan y su implementación. Normalmente suelen presentarse desarticulaciones significativas entre las instancias de formulación y las de implementación de los planes urbanos, independientemente de su especificidad y complejidad. En este contexto, la Comuna 8 de la Ciudad Autónoma de Buenos Aires resulta un caso de estudio pertinente de estas desarticulaciones, ya que condensa características particulares, como la existencia de sucesivos antecedentes de planes de sector urbano, y su rol como unidad territorial dentro de la subdivisión políticoadministrativa en Comunas, de reciente implementación en la ciudad. En esta ponencia se estudiará el recorrido realizado por el denominado Plan Maestro Comuna 8 - PMC8 - entre 2011 y la actualidad, en su proceso de legalización y legitimación. Interesa a esta investigación comparar este plan del poder ejecutivo, con la versión original y finalmente aprobada de la ley, en relación a los instrumentos de gestión urbana propuestos en cada caso, las áreas y temáticas abordadas, y los actores sociales activos durante el proceso legislativo.

Palabras clave: Comuna 8 - Buenos Aires - Plan Maestro - Urbanismo

\begin{abstract}
Within urban policies, Urban Planning (PU) is organized into three non-linear instances, which consist of the realization of a territorial diagnosis, the formulation of a plan and its implementation. Usually they present significant disarticulations between the instances of formulation and the implementation of urban plans, regardless of their specificity and complexity. In this context, Commune 8 of the Autonomous City of Buenos Aires is a relevant case study of these dislocations, since it condenses particular characteristics, such as the existence of successive antecedents of urban sector plans, and its role as a territorial unit, within politicaladministrative subdivision in Comunas, recently implemented in the city. This paper develops the process carried out by the so-called "Master Plan Commune 8" between 2011 and today, in its process of legalization and legitimation. It is interested in this research to compare this executive plan, with the original and finally approved version of the law, in relation to the urban management instruments proposed in each case, the areas and topics addressed, and the social actors active during the legislative process.
\end{abstract}

Keywords: Commune 8 - Buenos Aires - Master Plan - Urbanism 


\section{INTRODUCCIÓN}

La Tesis en curso se centra en el análisis de las posibilidades de articulación entre lo planificado y lo efectivamente implementado en los planes urbanos, ya que se considera que es el carácter de esta interfase lo que redundaría en la obtención de mayores o menores resultados exitosos. Conocer el grado de concurrencia o desfasaje entre las instancias de formulación e implementación permitirá ponderar el grado de eficacia / eficiencia de estos planes como instrumentos urbanísticos, e interpretar las causas y consecuencias de estos procesos.

Por otra parte, este análisis permitirá identificar el papel y el peso, de las dimensiones físico-ambiental y socio - cultural, en la viabilidad y factibilidad del proceso de planificación urbana. Esto cobra relevancia en la medida que un sector urbano planificado presenta mayor o menor permeabilidad al proceso de implementación, de acuerdo al grado de aceptación, involucramiento y acompañamiento de las propuestas por parte de los actores sociales y de la capacidad que el soporte territorial tiene de absorber e internalizar las propuestas derivadas de los planes.

Actualmente existiría un déficit en el seguimiento de los planes urbanos ya formulados, en relación a su evolución en la instancia de implementación. El fenómeno se asocia a la carencia de una cultura de evaluación y ajuste de esta clase de políticas públicas, que podría colaborar tanto con la optimización de los planes en si, como con el desarrollo de mejores metodologías de análisis, investigación y estudio de este instrumento, habitualmente utilizado en la gestión urbanística.

El sector de la actual Comuna 8 - C8 constituye históricamente el escenario de implementación de sucesivos planes de sector en diferentes contextos de desarrollo, que modificaron secuencialmente su estructura original respecto a la dimensión físicoambiental con grandes obras de infraestructura y equipamientos, condicionaron fuertemente sus formas de urbanización mediante la construcción de numerosos conjuntos habitacionales y su correlato desde la informalidad de las villas y los asentamientos, y donde el territorio comunal continúa sosteniéndose como enclave postergado en cuanto a su desarrollo y evitado por la inversión privada hasta el presente.

En esta ponencia se hará hincapié en la experiencia del PMC8 en su recorrido entre el poder ejecutivo y el poder legislativo de la ciudad de Buenos Aires. Se apuntará a identificar las continuidades y rupturas en relación a los ejes propuestos por este Plan, y respecto de la puja de poderes que los diferentes actores sociales y políticos protagonizaron y aportaron al debate que moldeó la actual ley vigente.

Ciudad de Buenos Aires - división en comunas. Fuente: GCBA

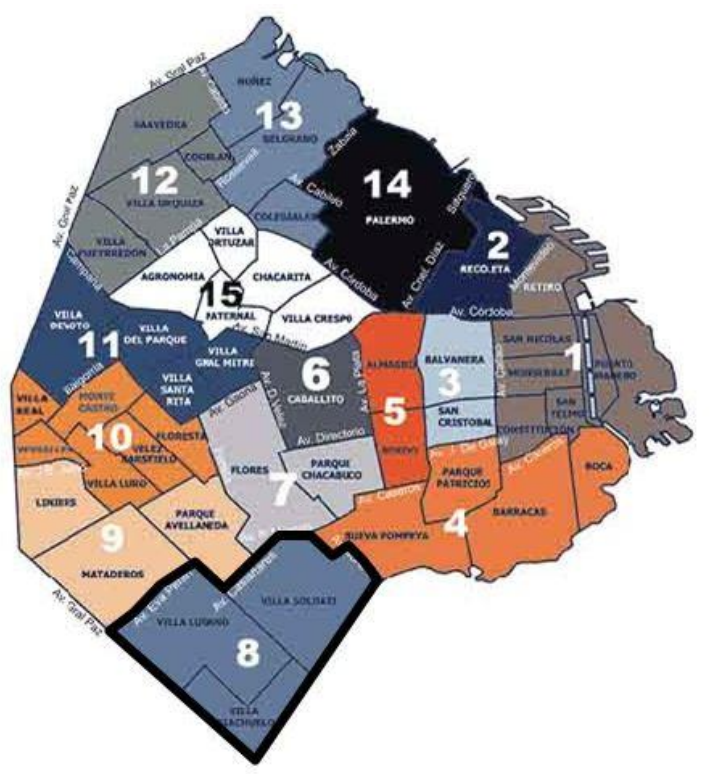


Para el desarrollo de esta investigación se trabajó con cuatro textos base:

A) El documento Plan Maestro Comuna 8, del año 2011, desarrollado dentro de la órbita de la dirección del planeamiento DGPLAN, del Ministerio de Desarrollo Urbano -MDU - del Gobierno de la Ciudad de Buenos Aires - GCBA.

B) El proyecto de ley original de Plan Maestro Comuna 8, de noviembre de 2012 y el Despacho en Mayoría y el Minoría de los legisladores.

C) El texto de ley aprobado en diciembre 2013, denominado "Promoción de las Actividades de la Producción e Industria Deportiva en la Ciudad Autónoma de Buenos Aires"

D) La ley vigente $N^{\circ} 5235$, aprobada en diciembre 2014.

Además, se realizó una recopilación de artículos periodísticos entre los años 2012 y 2014, que reflejan el impacto del avance de la ley en cada instancia, y las opiniones de los diferentes actores sociales involucrados.

En paralelo a la revisión y comparativa de estos documentos, se realizó un trabajo de cartografía para identificar los sectores dentro de la C8 en los cuales se proponía la implementación de diferentes instrumentos en cada versión del Plan. En estos mapas es posible visualizar las modificaciones y continuidades respecto de la localización, cantidades y dimensiones de estos sectores en cada uno de los documentos analizados.

\section{Breve historización del proceso}

La Comuna 8, al sur de Buenos Aires, posee actualmente una superficie total de 2180 has, cubiertas por sus tres barrios ${ }^{1}$, donde habitan unos 187.000 habitantes, con una densidad promedio comunal de 85 habs/ ha. Según el GCBA, estas son algunas de sus problemáticas más destacables actualmente²:

- El nivel más alto de informalidad laboral, el cual alcanza a más de 27 mil personas.

- El promedio del ingreso per cápita más bajo de la CABA.

- La mayor tasa de desocupación femenina de la CABA, con 11,1\%.

- Altas tasas de mortalidad infantil (10,9/1000).

- La menor esperanza de vida de la CABA, casi 7 años menor al promedio de la Ciudad.

- EL $2^{\circ}$ lugar en el ranking de delitos por portación ilegal de armas.

- Un alto índice de vulnerabilidad educativa (IVE) en el sector estatal de nivel primario.

- La tasa de embarazo adolescente duplica la del resto social.

En relación el despliegue histórico de las políticas públicas para esta Comuna, la injerencia del Estado en el desarrollo del área fue crucial para definir la actual configuración socio-económica y espacial de la Comuna 8 (Roitman - Szajnberg: 2015) ${ }^{3}$. Respecto a esta acción estatal vemos que "las contradicciones en la

\footnotetext{
1 Villa Lugano, Villa Soldati, Villa riachuelo.

${ }^{2}$ Extraído de la publicación " Proyecto urbano integral Comuna 8" disponible en http://www.buenosaires.gob.ar/planeamiento/planurbano-ambiental-comuna-8

3 Sobre este tema es posible consultar el siguiente artículo: "Evolución e impronta territorial de la planificación y gestión urbanística estatal en la Comuna 8 de la Ciudad Autónoma de Buenos Aires en el siglo XXI". Seminario Internacional de Investigación en Urbanismo - Barcelona - junio 2015.
} 
orientación de las intervenciones generaron impactos negativos, resultando en un territorio segregado en relación con el resto de la ciudad". (Di Virgilio: 2011)

\subsection{La construcción del Plan Maestro Comuna 8 dentro de la órbita del poder ejecutivo - 2010 - 2011}

El Plan Maestro Comuna 8 es un documento que pretende condensar propuestas de desarrollo urbanístico, en base a tres documentos precedentes:

a - el denominado Plan Urbano Ambiental - PUA - ley marco para todas las propuestas que se realicen dentro de la CABA.,

b - el Modelo Territorial Buenos Aires 2010 - 2060 - su contraparte grafica, en la cual se cuantifican y ponderan los diferentes sectores de la CABA en relación a una serie de indicadores diseñados a tal fin, y se plantean las metas a alcanzar en el futuro en relación a estas mediciones.

c - El Diagnostico Territorial de la Comuna 8, realizado en 2010, que hace pie en la información de ambos documentos anteriores para caracterizar a la Comuna, de la misma forma que fueron realizados similares informes para las demás 14 reparticiones, dentro del flamante proceso de descentralización de la gestión de gobierno de la CABA.

4 Di Virgilio y otros (2011) " Barrios al sur: Villa Lugano, Villa Riachuelo, Mataderos, Parque Patricios y Villa Soldati a través del tiempo". Publicación del Instituto Gino Germani, Buenos Aires. 
EI PMC8 se vale de las 6 temáticas que incluye el PUA (Hábitat y Vivienda, Estructura y Centralidades, Producción y Empleo, Espacio Público, Transporte y Movilidad y Patrimonio Urbano) y en conjunto con el diagnóstico y análisis del Modelo Territorial, presenta lineamientos generales para la Comuna 8.

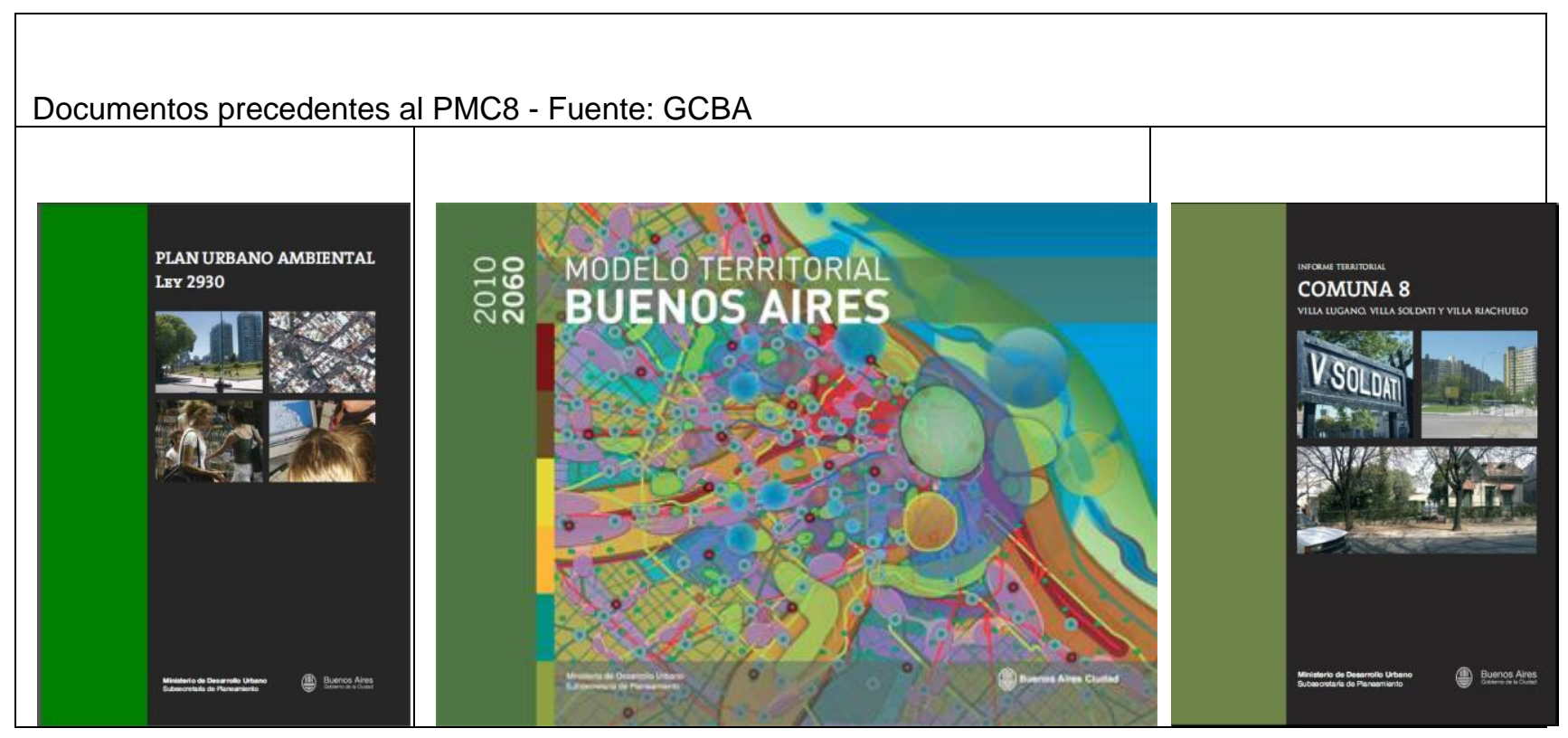

Dentro del desarrollo del plan se realizaron instancias participativas en la cuales algunos representantes de los diferentes actores sociales implicados en el plan, pudieron expresar sus opiniones, que supuestamente fueron consideradas para la realización del documento.

\subsection{El proyecto de ley: Plan Maestro Comuna 8 - 2012}

Dentro de la órbita del Partido Propuesta Republicana - PRO, y en correlato con el Plan realizado dentro del poder ejecutivo, se diseña un proyecto de Ley denominado "Plan Maestro Comuna 8", que aporta algunos instrumentos de planeamiento, gestión, normativos y de promoción para la efectiva ejecución de los lineamientos propuestos. Este fue impulsado por legisladores del PRO del poder legislativo de la CABA, en Octubre del año 2012.

\subsection{Modificación al proyecto - Del plan Maestro al Distrito del deporte.}

El documento aparentemente recibió numerosas críticas por parte de la oposición en la legislatura y de varios colectivos sociales, y recién logra la aprobación en primera lectura en diciembre de 2013, luego de numerosas modificaciones, bajo el nombre de "Promoción de las Actividades de la Producción e Industria Deportiva en la Ciudad Autónoma de Buenos Aires"5. En abril de 2014 se realiza la audiencia pública, que constituye un requisito legal, aunque es "no vinculante", y finalmente en diciembre de ese año se realiza la aprobación final de la ley $5235^{6}$.

\section{Comparación y análisis del contenido de los documentos}

\subsection{Síntesis de propuestas del Informe diagnostico para la elaboración del Plan de Comuna 8.}

\footnotetext{
5 Texto completo disponible en el número 4330 del Boletín oficial - http://boletinoficial.buenosaires.gov.ar/

6 Texto completo disponible en http://www2.cedom.gov.ar/es/legislacion/normas/leyes/ley5235.html
} 
El documento denominado: "Informe diagnostico para la elaboración del Plan de Comuna 8. Desarrollo urbano y social de la Comuna 8", fue elaborado dentro de la órbita de la Secretaria del Planeamiento, del Ministerio de Desarrollo Urbano del GCBA durante el año 2011. Este documento se organiza en 3 partes:

a - Características de la ciudad actual en la Comuna 8 (Demográficas, mercado Inmobiliario, construcción, usos del suelo). Este capítulo retoma y actualiza la información presentada en el diagnostico comunal realizado en 2010 por la misma repartición del poder ejecutivo local.

b - Indicadores de sustentabilidad - situación actual. Este capítulo retoma el sistema de indicadores utilizado en el Modelo Territorial BA 2010 - 2060, y presenta los resultados de la medición de estos en la Comuna 8, obteniendo unos valores parciales para cada uno de los 6 ejes definidos dentro de la metodología, y un

valor promedio final de estos, denominado Índice de Sustentabilidad Urbana - ISU. Este valor es de 0,706, levemente por encima del promedio de la CABA - 0,68.

c - Lineamientos de Planeamiento. En este capítulo se plantea que la totalidad del documento constituye un instrumento de planificación, que permite profundizar los lineamientos propositivos, y que su objetivo "es la planificación de las intervenciones y la programación en el tiempo con criterios de eficiencia y eficacia"'.

Más adelante, bajo el titulo: "Características de la Ciudad Deseada en la Comuna 8", se revisan los indicadores más relevantes para la comuna, y se muestra el contrapunto entre los valores actuales, y los "futuros" deseables en cada caso.

Dentro de los denominados "lineamientos propositivos para la Comuna 8" se retoman los 6 ejes de trabajo del PUA para enunciar los lineamientos propuestos en cada caso. Estos poseen aleatoriamente mayor 0 menor grado de especificidad.

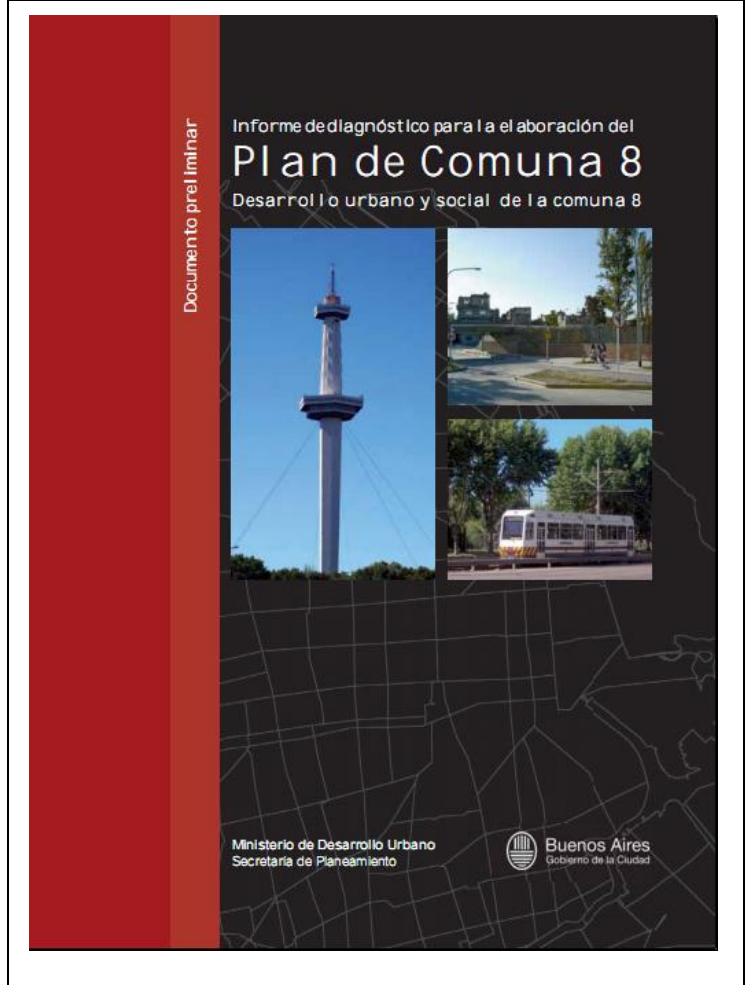

El primer eje desarrollado: Estructura y Centralidades propone: la creación de 3 economías especializadas; el desarrollo de un corredor productivo de alta densidad; la consolidación de la sede comunal como

\footnotetext{
${ }^{7}$ Extraído del "Informe diagnostico para la elaboración del Plan de Comuna 8. Desarrollo urbano y social de la Comuna 8" - 2011 - . Pag . 53
} 
centralidad política; la generación de nuevas economías de aglomeración locales y el desarrollo de centralidades intermodales asociadas al transporte público.

El segundo eje, Hábitat y vivienda, propone: la definición de una red de "Macromanzanas" con zonas de prioridad para los peatones, apertura de calles en los grandes equipamientos preexistentes, y consolidación de la trama urbana; la creación de zona de consolidación de media densidad (en paralelo a la Av. Roca y el Riachuelo) y otra de baja densidad, con criterios de preservación y protección morfológica, patrimonial; la urbanización de las villas y asentamientos, y la residencializacion de los frentes de los clubes deportivos.

Para el tercer eje: Espacio Público, se plantea la necesidad de la generación de nuevos espacios verdes públicos, para reducir el índice de compacidad (90 has.); el incremento del arbolado en un 50\% (11.000 nuevos árboles); y el desarrollo de 3 nuevos espacios verdes para incrementar la proximidad a espacios verdes útiles - EVU, de 600 a $350 \mathrm{mts}$.

Además, se proponen obras publicas de creación y puesta en valor de corredores sobre las avenidas Roca, Fernandez de la Cruz y 27 de febrero; la Integración de las grandes superficies verdes existentes, la generación de nuevos espacios verdes a escala urbana y micro y de áreas de Edificación sustentable, en cercanías al Riachuelo; y la incorporación de criterios de sustentabilidad hídrica.

Para el cuarto eje, Transporte y movilidad, se propone el desarrollo de la conectividad entre la comuna y el resto del área metropolitana, mediante infraestructuras sobre el Riachuelo y la Av. Gral Paz. (y en coherencia con el objetivo de la conformación de nuevos tejidos urbanos); la mejora de los ferrocarriles mediante alguna solución tecnológica de las barreras urbanas; la generación de una red de Metrobús utilizando los principales ejes de la comuna; y el Impulso de nuevos nodos de intercambio (transporte densidad habitacional - actividades económicas).

Para el quinto eje, Producción y Empleo, se propone: el desarrollo de 2 millones de m2 residenciales, de $930.000 \mathrm{~m} 2$ para locales y de $900.000 \mathrm{~m} 2$ de nuevo Espacio Publico Útil; el impulso y generación de nuevas economías de aglomeración; la expansión de las economías de aglomeración preexistentes; la generación economías especializadas; el impulso a la actividad productiva de alta intensidad con la creación de un corredor productivo en el eje del Riachuelo y la incorporación de usos mixtos o especializados en los nuevos tejidos urbanos que se desarrollarán en el área.

Por último, para el eje Patrimonio Urbano propone: definir criterios de crecimiento morfológico acorde con el paisaje barrial de baja densidad; priorizar el análisis y catalogación de edificios de valor monumental en ciertos entornos; definir los conjuntos habitacionales como patrimoniales y declarar Áreas de Patrimonio Urbano; definir criterios morfológicos de protección del paisaje barrial, potenciar la estructura urbana de baja densidad preexistente y respetar la morfología urbana actual (PB +2 pisos).

En el marco de la investigación se realizó un esquema síntesis de las propuestas para los 6 ejes, que resume las acciones planteadas en el documento. Este esquema permite visualizar que en Plan posee una visión integral del territorio, en la cual la totalidad de este es abarcada con proyectos y programas vinculados mayormente al desarrollo de subcentralidades, asociadas transporte y a la puesta en valor del espacio público. 


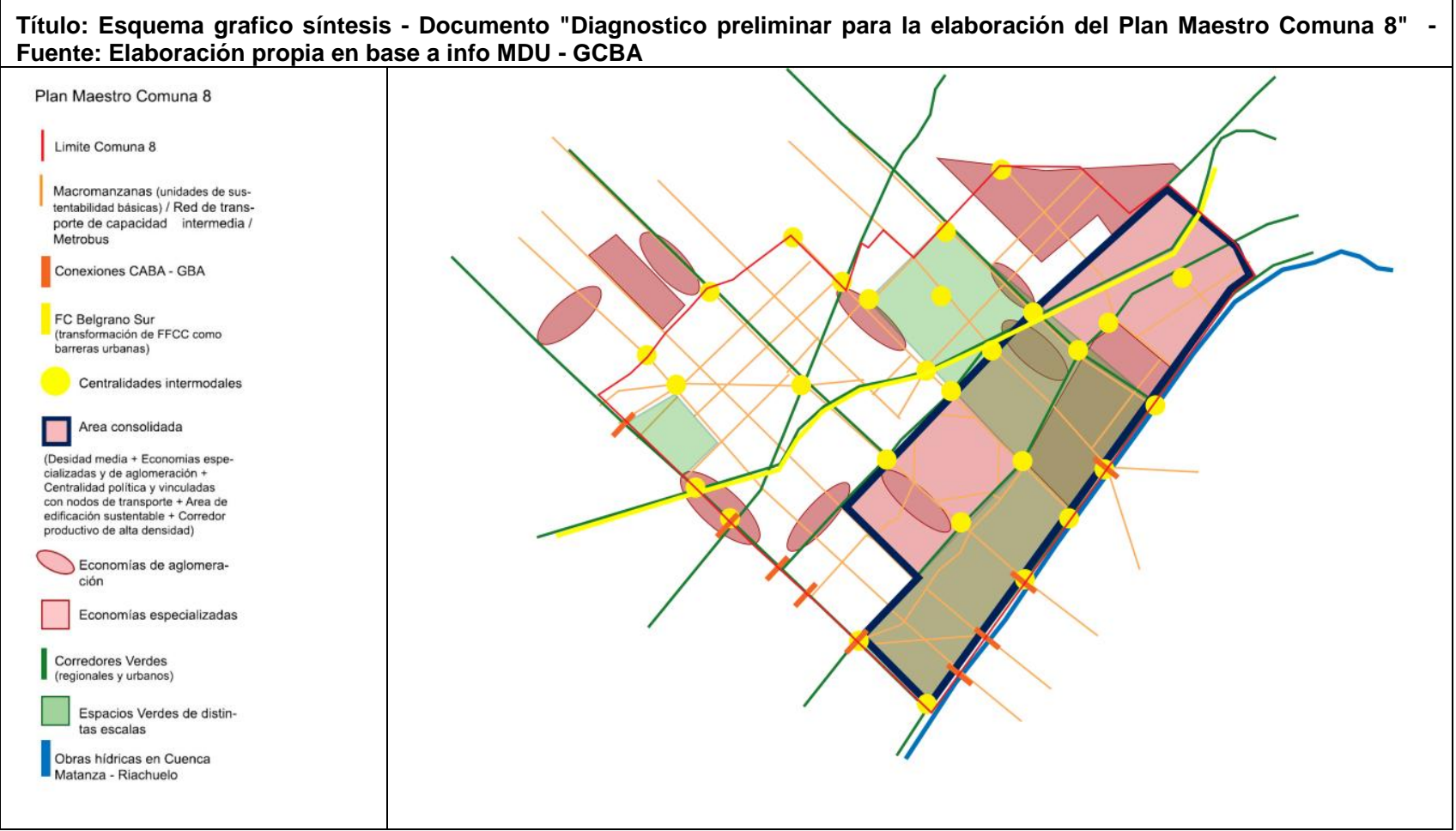

3.2 Proyecto de Ley Plan Maestro Comuna 8 - PMC8 - año 2012.

Esta versión del proyecto de ley fue elaborada por los diputados oficialistas dentro de la legislatura de la CABA, y se debatió pero no llegó a aprobarse ${ }^{8}$. En relación al Plan del poder ejecutivo, esta versión de la ley apuntaba a su efectiva ejecución, a través de la implementación de 11 instrumentos:

1) El traspaso a la Corporación Buenos Aires Sur - CBAS.SE. - de 11 predios del GCBA, y el cambio de normativa para su urbanización como barrios. Los fondos obtenidos $x$ su enajenación serian utilizados para la urbanización de villas y puesta en valor de los conjuntos habitacionales.

2) La venta a los clubes deportivos de las tierras fiscales (actualmente ocupadas por estos en forma de concesiones), y el cambio de normativa de estos predios para la densificación de sus bordes con usos residenciales y comerciales.

3) La creación del denominado "Distrito del Deporte". (Polígono con excepciones impositivas).

4) La creación del Distrito Biotecnológico (polígono con excepciones impositivas).

5) La construcción del instituto "Ciencias de la vida".

8 El documento está compuesto por 10 capítulos: Propuestas - Instrumentos normativos- Clubes Producción y Empleo - Incentivos fiscales - Concesiones - Villa Olímpica - Cuenca Riachuelo - Banco Ciudad - Autoridad de Aplicación. 
6) La construcción del predio "Ferias de Buenos Aires".

7) La implementación de incentivos fiscales para ambos distritos para quienes inviertan en los rubros definidos en cada caso (descuento en Ingresos Brutos, exención pago de sellos, impuesto inmobiliario y otros), y asignación de partida presupuestaria por 10 años (185 millones de pesos en el primer año) para la gestión de estos.

8) La desafectación del dominio público de la CABA de grandes predios (Parque de la Ciudad, Parque de las Victorias, Parque Roca, y Autódromo) para su transferencia a la CBAS.SE., y la generación de concesiones para clúster automotriz, gastronomía, infraestructura cultural, Industrial, de turismo, estadios, centros de convenciones y exposiciones, y propuestas con temática deportiva.

9) La construcción de la Villa Olímpica - viviendas para alojar a los deportistas en las olimpiadas juveniles del 2018 y su posterior incorporación al stock existente en la comuna.

10) La articulación con la Autoridad de Cuenca Matanza - Riachuelo - ACUMAR para la realización de proyectos articulados con municipios vecinos, respecto a la temática ambiental.

11) Creación de líneas de Crédito del Banco Ciudad para la compra de viviendas, la financiación de las operaciones de venta a los clubes de los terrenos actualmente concesionados, la mudanza de empresas a sus respectivos distritos temáticos, y la reforma y construcción de inmuebles dentro de la Comuna.

En el marco de la investigación se realizó por una parte un esquema síntesis de las propuestas, que resume las acciones planteadas en el proyecto de ley. En este esquema es posible verificar el despliegue de los instrumentos propuestos en el territorio comunal, observando áreas con mayor o menor impacto. 
Título: Esquema grafico síntesis - Documento "Proyecto de ley: Plan Maestro Comuna 8" - 2012-

Fuente: Elaboración propia en base a info MDU - GCBA

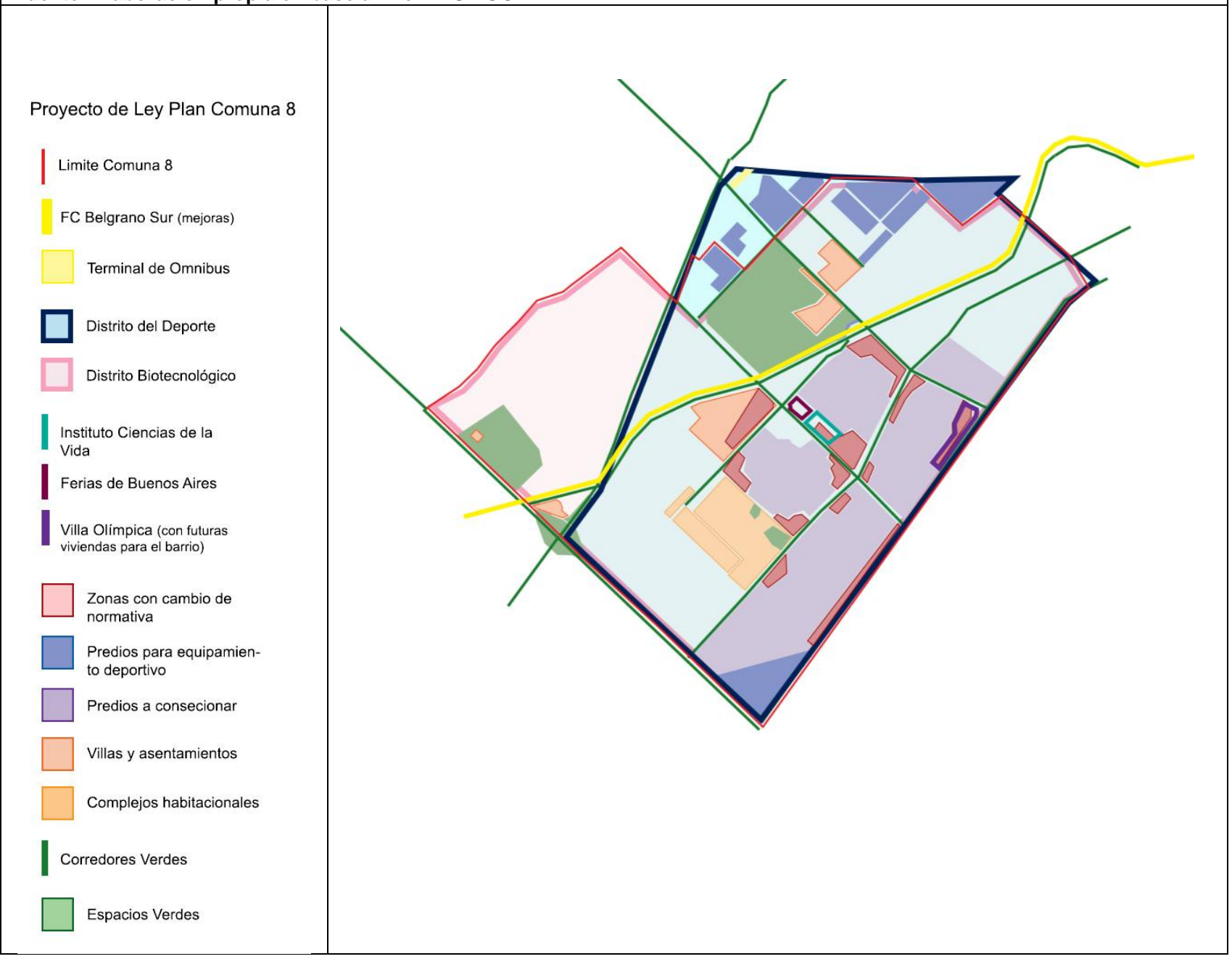

Respecto a las continuidades y rupturas entre el documento "plan" del poder ejecutivo, y este proyecto de ley, se realizó una tabla comparativa que permitió cuantificar niveles de correlación y asociabilidad entre ambos: 


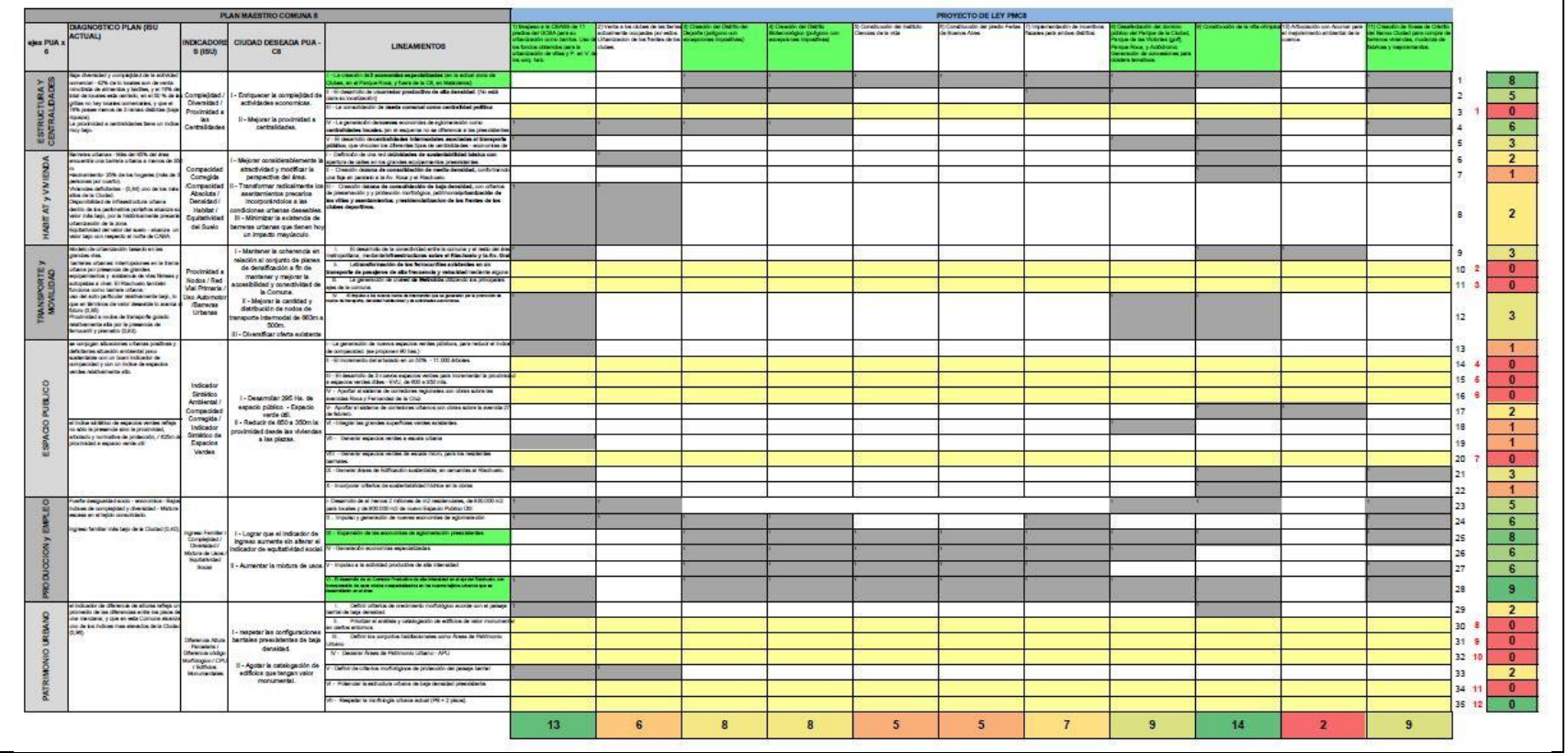

Para este análisis, se consideraron por una parte las correlaciones entre lo propuesto por el plan, y los instrumentos planteados en el proyecto de ley, registrando los puntos de contacto entre ambos.

En este análisis se observo que, de las 35 líneas de acción planteadas en los 6 ejes de trabajo del plan, solo 23 de estas (65\%) encontraban un correlato con lo propuesto en la ley. De estas 23 coincidencias, solo 3 de ellas poseían un alto nivel de correlación ( eran abordadas por más de 7 de las 11 propuestas de la ley). Estas 3 propuestas se agrupan en torno a la generación y fomento de centralidades económicas y actividades productivas.

En relación a los niveles de asociatividad, se observo que, de las 11 propuestas del proyecto de ley, 6 de estas alcanzaron altos valores (8 o más vinculaciones con las propuestas del plan). Para estos 6 casos, los temas abordados giran en torno a la creación de nuevos barrios, la implementación de distritos económicos y clusters temáticos por rama de actividad productiva, y la generación de líneas de crédito para el acceso a la vivienda y las mejoras en la infraestructura de la industria local.

De esta forma, es posible afirmar que este proyecto de ley, si bien lo lograba abarcar la totalidad de las propuestas del Plan, si era coherente con este respecto de los instrumentos que proponía, en relación a este documento-marco.

\subsection{Proyecto de Ley "Distrito del Deporte" - Aprobación en primera lectura - Dic. 2013}

A partir del proyecto original, se realizaron numerosos ajustes al texto como consecuencia del debate en la legislatura y las pujas de poder entre actores intervinientes. La versión ajustada del texto fue aprobada en comisión y publicada en el boletín oficial en enero 2014, y los principales ajustes y continuidades fueron:

- Se mantiene la creación del Distrito del Deporte, que para a ser el instrumento estructural de 
gestión propuesto. Se mantienen la exenciones impositivas y demás recursos propuestos para su implementación.

- Se eliminan las once zonas a urbanizar, conservándose solamente el Área Olímpica que se traslada del Parque Roca al Parque de la Ciudad.

- Desaparece el capítulo de Clubes y la respectiva venta de terrenos a estos.

- Se desestima la creación del Distrito biotecnológico y la consecuente construcción del instituto "Ciencias de la Vida". También se elimina la propuesta de creación del predio Ferias de Buenos Aires.

- Se elimina el capítulo de concesiones, y la transferencia a la CBAS.SE. de los grandes predios.

- Desaparece el capítulo de articulación con la ACUMAR, y la propuesta de líneas de crédito del Banco Ciudad.

Además, en el texto ajustado se incluye:

- Un nuevo capítulo denominado "Barrios nuevos", en el cual se propone la modificación del código de planeamiento para los Distritos "U31" de la comuna coincidentes con las villas y conjuntos habitacionales, cuyo carácter es la urbanización con criterios de radicación definitiva destinado a viviendas, actividades productivas de carácter familiar y equipamiento comunitario. Los usos propuestos agrupan actividades residenciales de densidad media y media baja, admitiéndose usos mixtos compatibles con la vivienda. En este capítulo se definen las localizaciones, la nueva normativa respecto a constructividad y usos, y el registro de las edificaciones en el Catastro del GCBA.

- La definición del Ministerio de Desarrollo Económico como autoridad de aplicación del Distrito del Deporte, y el consecuente desplazamiento del ministerio de Desarrollo Urbano.

- La propuesta de un Plan Educativo para la promoción de la industria deportiva, para lo cual se asigna un predio de 7 hectáreas, perteneciente al IVC para la construcción de infraestructura educativa.

- La propuesta de Promoción de la Inserción laboral local, que plantea un cupo mínimo de empleados locales a emplear por parte de los comerciales que ingresen al registro del Distrito del Deporte.

En el marco de la investigación se realizó un esquema síntesis de las propuestas, que resume las acciones planteadas: 
Título: Esquema gráfico síntesis - Documento: Ley aprobada en primera lectura: Distrito del Deporte" - 2013

Fuente: Elaboración propia en base a publicación en el boletín oficial

Ley Inicial Distrito del Deporte

Limite Comuna 8

Distrito del Deporte

Villa Olimpica (zona a urbanizar + promoción laboral local + viviendas)

Predio de Plan Educativo

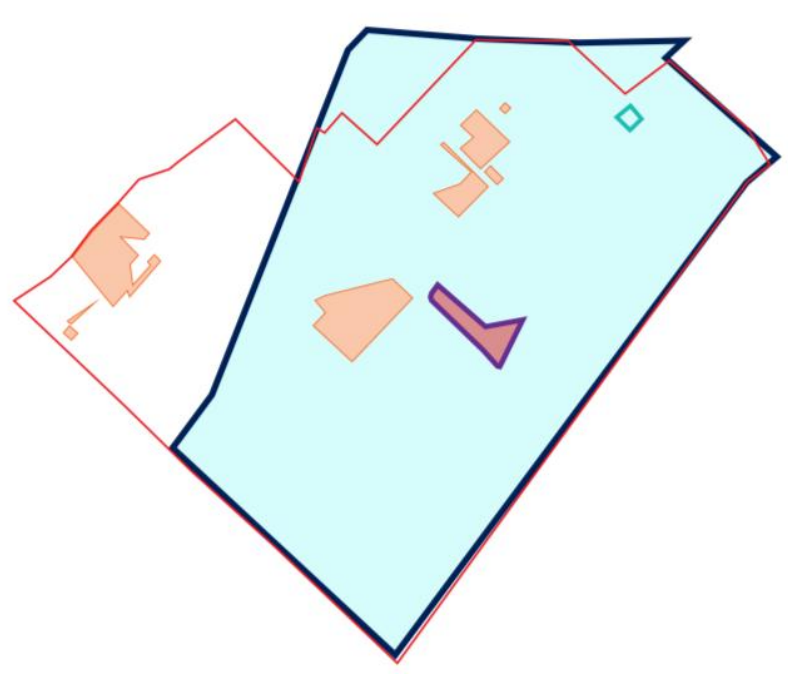

"Barrios Nuevos"

En este esquema es posible verificar la reducción del impacto de las propuestas en la Comuna, en relación a la versión original del proyecto de ley. La propuesta queda reducida a la construcción de la Villa Olímpica, a la puesta en funcionamiento del Distrito del Deporte y al impulso de los procesos de regularización de villas y asentamientos.

Nuevamente, respecto a las continuidades y rupturas entre el documento "plan" del poder ejecutivo, y este nuevo proyecto de ley, se realizó una tabla comparativa que permitió cuantificar niveles de correlación y asociabilidad entre ambos. En esta tabla es posible verificar que los niveles de correlación Plan - Ley aumentaron, detectándose 4 casos de 35 en el cual la correlación es alta (4 o más vinculaciones). Estos temas son coincidentes a su vez con los detectados en la versión original de la ley (generación y fomento de centralidades económicas y actividades productivas).

Respecto a los niveles de asociatividad, vemos que, de los 7 temas - instrumentos propuestos, 4 de ellos posee valores altos (mayores a 8). Los temas abordados en estos son, en algunos casos, coincidentes con los identificados en el proyecto de ley original (la creación de nuevos barrios y la implementación de distritos económicos), a los que se suma la regularización de asentamientos informales y el gerenciamiento de la Villa Olímpica. 
Tabla comparativa - PMC8 - Proyecto de ley 2013 - Niveles de Correlación y asociabilidad entre instrumentos propuestos.

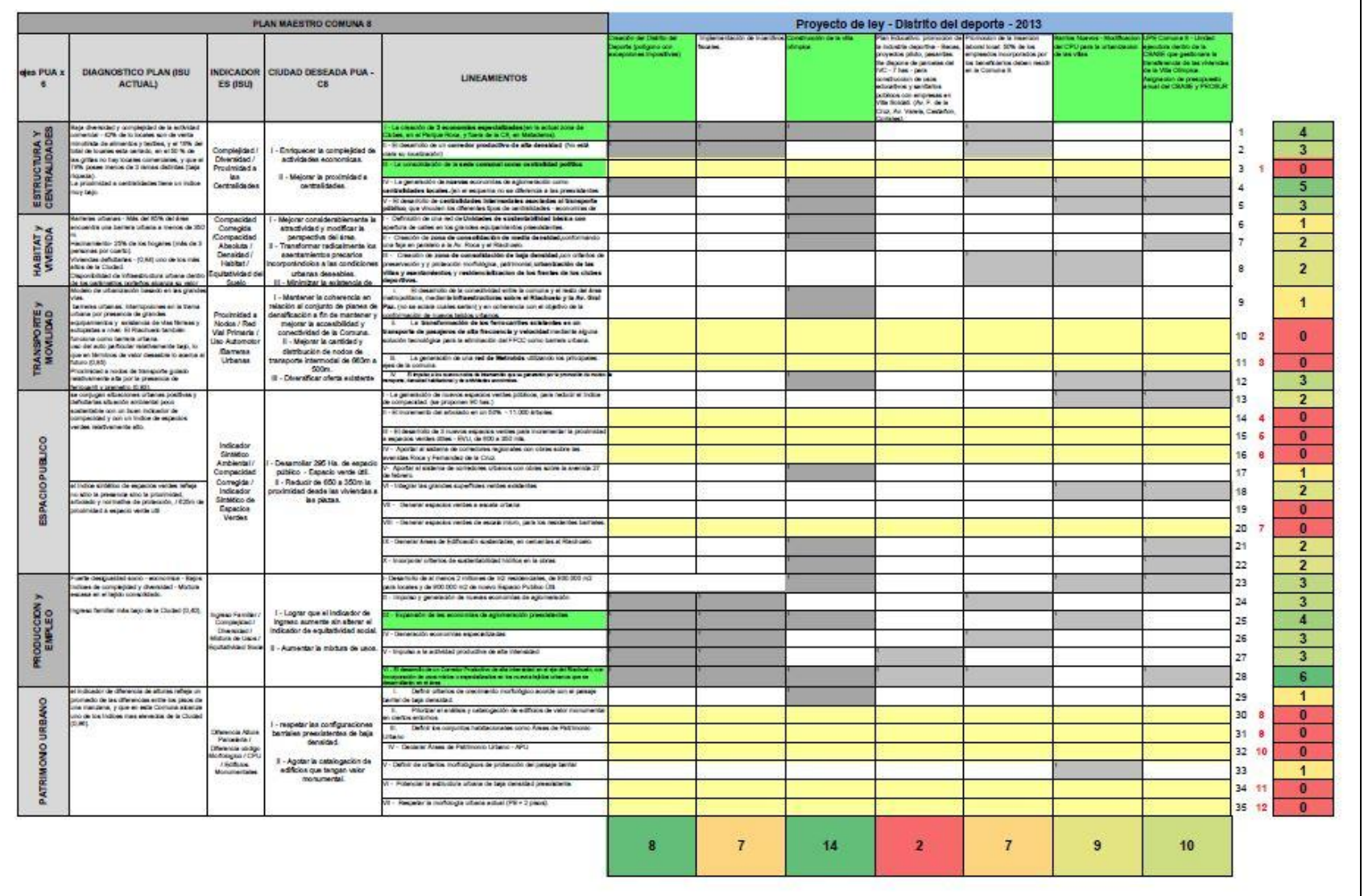

3.4 - Ley "Distrito del Deporte" - Versión aprobada- Diciembre de 2014

En base a los aprobado en comisiones en 2013, luego de la audiencia Pública (realizada en abril 2014) se aprueba la versión final de la Ley Distrito del Deporte en diciembre de 2014, y se publica en el Boletín oficial en abril de 2015.

Respecto al texto aprobado en comisiones en 2013, no se presentan mayores diferencias. Sin embargo se detectan algunos cambios:

- Se eliminan los artículos que hacían mención a los concursos de arquitectura a realizarse para la construcción de los edificios, y a la transferencia de las viviendas de la Villa Olímpica al IVC para destinarlas a los vecinos de la Comuna.

- Se suma un nuevo capítulo que propone la creación de la Unidad de proyectos especiales - UPE Comuna 8 - , Unidad ejecutora dentro de la CBAS.SE. que gestionara la transferencia de las viviendas de la Villa Olímpica en diferentes modalidades.

- En este capítulo también se asigna a esta UPE un presupuesto determinado por la legislatura, de monto mínimo del $25 \%$ del total de los presupuestos asignados a la Corporación Buenos Aires Sur y al Programa de Regularización y Ordenamiento del Suelo Urbano (PROSUR HABITAT). 
En el marco de la investigación se realizó un esquema síntesis de las propuestas, que resume las acciones planteadas. Respecto a la comparativa de este esquema con la versión anterior de la ley de Distrito del Deporte, no se encuentran mayores cambios. Las diferencias se manifiestan en relación a cuáles serán las autoridades de aplicación responsables de gerenciar la construcción y la asignación de viviendas. En este punto, el Instituto de la Vivienda es desplazado y reemplazado por la Unidad de Proyectos Especiales y la Corporación BA Sur.

Título: Esquema gráfico síntesis - Documento: Ley aprobada "Distrito del Deporte" - 2014

Fuente: Elaboración propia en base a publicación en el boletín oficial

Ley Final Distrito del Deporte

Limite Comuna 8

Distrito del Deporte

Villa Olimpica (zona a

urbanizar + promoción

laboral local + viviendas)

Predio de Plan Educativo

"Barrios Nuevos"

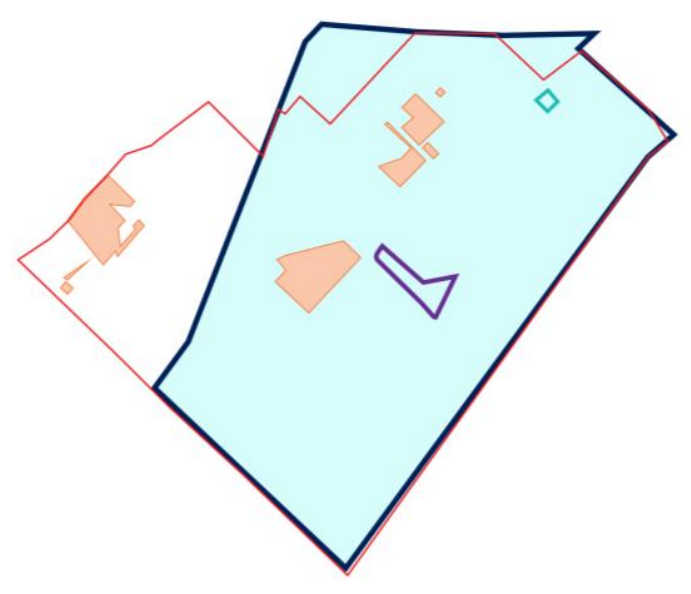

En paralelo, a modo de síntesis de la revisión de las tres versiones de la ley, se realizó la siguiente tabla que permite visualizar las continuidades y rupturas respecto de los instrumentos propuestos. De esta forma es posible contratar que, de las 11 propuestas de la versión original, 6 de ellas son eliminadas, a la vez que se suman 3 nuevos instrumentos vinculados a la regularización de asentamientos informales preexistentes, y el fomento de políticas educativas y de empleo local. 


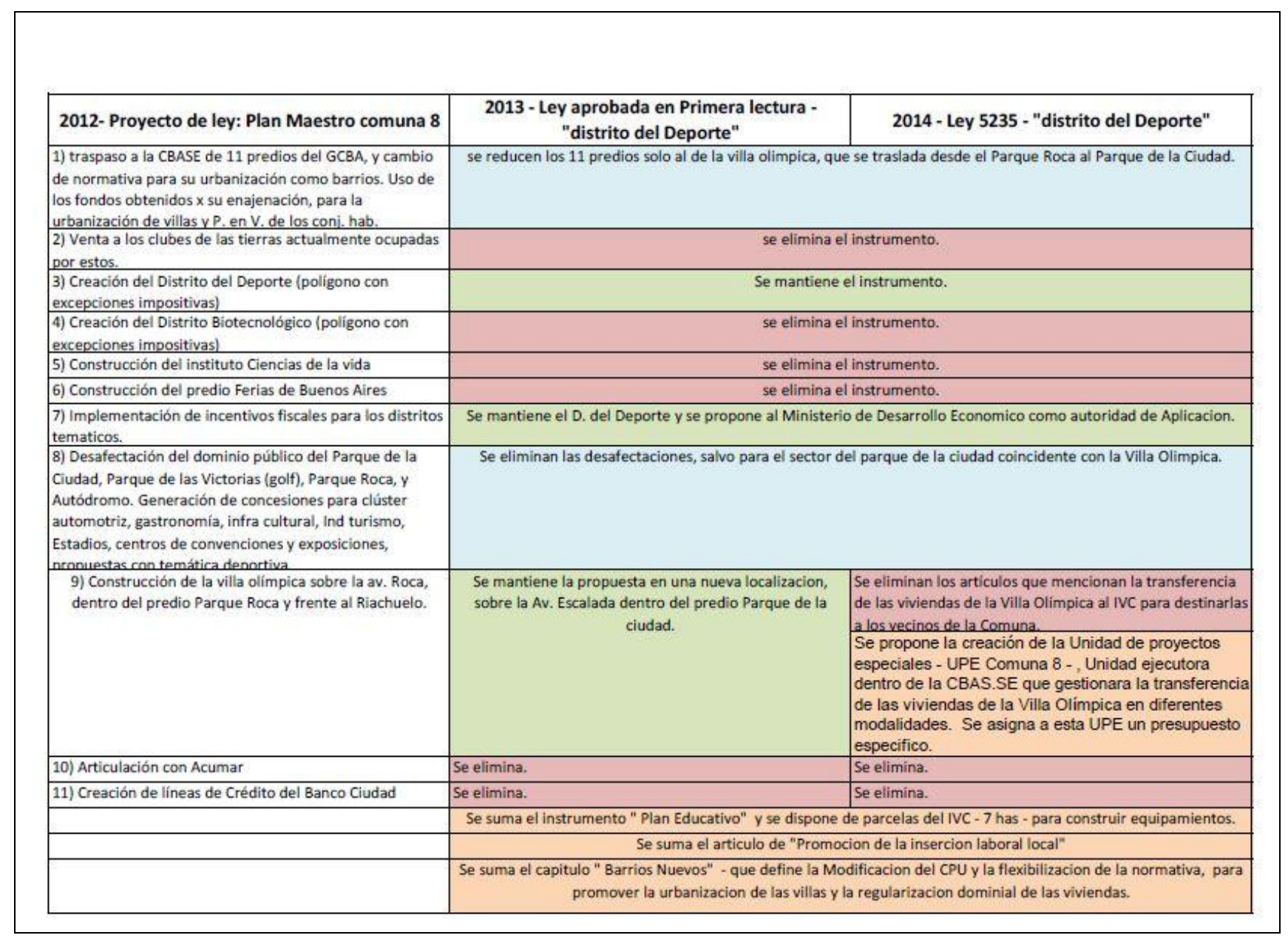

\section{El plan Maestro y los aportes de los actores sociales intervinientes}

El proceso de realización del Plan Maestro Comuna 8 incluyó en junio y julio de 2012 una serie de reuniones en la Comuna con diferentes representantes locales ${ }^{9}$, denominadas "Conversación abierta hacia el desarrollo de la Comuna 8". Según figura en algunos medios relevados, algunos participantes fueron ${ }^{10}$ :

El propio Gobierno de la Ciudad, que presentó 60 propuestas organizadas en 6 ejes (coincidentes con los del plan) a través de una propuesta participativa con mesas de trabajo grupales, mapeos y planillas.

Los comuneros de los partidos fuera del oficialismo en 2012 en CABA (Proyecto Sur, Frente Para la Victoria entre otros), que firmaron una resolución común donde solicitaron que la propuesta sea tratada en audiencias públicas antes de que la voten en el recinto.

La organización "Colectivo por la igualdad"11, dirigida por Facundo de Filippo, que reclamó por una mayor participación vecinal y de los funcionarios de la Comuna, y también una mayor difusión de la información

\footnotetext{
${ }^{9}$ info oficial disponible en : http://www.buenosaires.gob.ar/planeamiento/ciudadenred/jornadas-y-muestras/conversacion-abierta-haciael-desarrollo-de-la-comuna-8

${ }^{10}$ Info extraida de la publicacion de Diario Z" Plan Maestro Comuna 8: Cirugía mayor de espacios verdes" - 30 de noviembre de 2012 disponible en http://www.diarioz.com.ar/\#!/nota/plan-maestro-comuna-8-cirugia-mayor-de-espacios-verdes-26374/

${ }^{11}$ El Colectivo por la Igualdad es una organización política y social que desarrolla su trabajo militante en la Ciudad de Buenos Aires, abordando problemáticas vinculadas a las áreas de vivienda, ambiente, derechos humanos, civiles, cultura y transporte, entre otras. Entre sus principios fundantes, se encuentran la horizontalidad para el debate y la toma de decisiones, y el autofinanciamiento económico. http://cxigualdad.blogspot.com.ar/p/quienes-somos.html
} 
acerca de la puesta en valor de espacios verdes existentes. (Esta organización manifestó en estas reuniones que el expediente que sería tratado en el recinto transfiere al fondo de la CBAS.SE. unos 200.000 $\mathrm{m} 2$, y que entre lo que se vendería y lo que se pondría en concesión, se alcanzarían las 500 hectáreas, casi una cuarta parte de la superficie de la Comuna 8).

Además, acerca del proyecto de ley de 2012, se expresaron, entre otros, los siguientes legisladores, que participaron del documento denominado "Despacho en minoría" del proyecto de ley Plan Maestro Comuna 8 , en la reunión de asesores ${ }^{12}$ :

- Adrián Camps, legislador por el Partido Socialista Auténtico, que afirma que el proyecto de ley, al proponer la enajenación de tierras públicas para la creación de nuevos barrios, contradice la ley del PUA, que apunta a la preservación y ampliación de las áreas verdes existentes en la ciudad ${ }^{13}$. El legislador advirtió sobre el riesgo de conceder a sectores privados los predios de dominio público por hasta 30 años "sin ninguna condición", situación que podría llevar a que el GCBA no obtenga mayores beneficios en relación a los que si pudieran obtener los inversores privados.

- Rocío Sánchez Andía, legisladora por Coalición Cívica, que cuestiona la figura de la CBAS.SE. como articuladora de políticas habitacionales, entendiendo que estas atribuciones le pertenecen al IVC. Sanchez Andía también cuestiona la estrategia de financiación para la urbanización de las villas a través de la venta de terrenos públicos: "Uno de los argumentos para que se hiciera cargo la Corporación del Sur de la urbanizanización en el sur era la burocracia y el tiempo que tardaba el IVC en hacer las obras, pero la Corporación no mostró mayor eficacia. No entendemos por qué siguen planteándola como autoridad de aplicación para política habitacional y para urbanización en villas". Según esta legisladora, "La ley marco que estamos discutiendo no tiene nada de ley marco, tiene un fin que es poner terrenos públicos al servicio de privados"14.

Dentro del propio texto del Despacho en Minoría, es posible encontrar numerosas objeciones al proyecto de ley original: la falta de revisión del texto en las comisiones pertinentes; la carencia de un diagnostico del sector que fundamente las propuestas planteadas y de instrumentos de evaluación y monitoreo; o la imprecisión e indefinición de las propuestas, "que tornan al mismo (plan) en un conjunto aleatorio de ideas que solamente parecen destinadas a movilizar por medio de herramientas de mercado gran parte del patrimonio público de suelo urbano en esa Comuna -tal vez la más importante concentración de suelo público en la Ciudad-, y no un plan armónico que tienda a la mejora de las condiciones de vida en la misma ${ }^{15 ",}$ entre otras.

Por otra parte, los medios de comunicación acompañaron el desarrollo del este proceso, difundiendo y a la vez distorsionando el avance de la ley, que si bien dejó de llamarse "Plan Maestro" a partir de la aprobación en primera lectura del Distrito del Deporte, esta mantuvo la denominación de Plan en la prensa. Como ejemplos pueden citarse a Noticiario Sur, que tituló el 6 de diciembre de 2013, "La legislatura voto el Plan de Comuna8"16, refiriéndose a la aprobación del Distrito del Deporte; y a la propia Legislatura porteña publicó en 2014 en su página oficial: "se realizó la audiencia pública por el Plan Maestro Comuna 817", siendo que en esta instancia la ley ya había sido aprobada en primera lectura como "Distrito del Deporte". El portal web

\footnotetext{
${ }^{12}$ Con fecha del 19 de noviembre de 2012.

${ }^{13}$ Camps plantea que "los espacios que se incorporan como Urbanización Parque en general son áreas que ya están parquizadas, laterales de autopistas, espacios muy pequeños, bulevares; y los que se desafectan como Urbanización Parque son espacios verdes que la gente sí utiliza".

14 Info extraída de la publicación de Diario Z" Plan Maestro Comuna 8: Cirugía mayor de espacios verdes" - 30 de noviembre de 2012 - disponible en http://www.diarioz.com.ar/\#!/nota/plan-maestro-comuna-8-cirugia-mayor-de-espacios-verdes-26374/

${ }^{15}$ Extraído del documento "Despacho en Minoría". Legislatura porteña - 19 de noviembre de 2012. Despacho № 0425/13: Comisiones de Planeamiento Urbano y de Presupuesto, Hacienda, Administración Financiera y Política Tributaria. Despacho de Mayoría: Ley: Plan Maestro Comuna 8. Despacho de Minoría: Resolución: Archivo. (Exp. 3257-D-12, Diputados Spalla y Ritondo). Ley $1^{\text {a }}$ Lectura (40 votos- Art. 82 , inc. 4 y 89 , inc. 4 CCBA). Tiene una observación del diputado Bodart.
}

\footnotetext{
16 disponible en: http://www.noticiariosur.com.ar/titulos/destacados/la-legislatura-voto-el-plan-de-la-comuna-8

17 Publicado el 22 de abril de 2014. Disponible en http://www.legislatura.gov.ar/noti_ver.php?ver=3461
} 
Minuto Uno, tituló "EI PRO aprobó su plan Maestro para la Comuna $8^{18 "}$ el 12 de diciembre de 2014, cuando se realizó la votación final.

\section{Algunas conclusiones}

A partir de la revisión de los 4 documentos, es posible observar continuidades y rupturas entre los postulados iniciales del Plan Maestro del poder ejecutivo, y el texto aprobado en la legislatura.

El Plan y su correspondiente apoyatura legal constituida por la primer versión del texto de ley de 2012, conforman un primer tandem que sostiene cierta coherencia en la medida que el texto del proyecto de ley opera como caja de herramientas para la realización de lo propuesto. Sin embargo, también podría interpretarse que las indefiniciones en el documento "Plan" del poder ejecutivo dan vía libre a los legisladores para diseñar las propuestas instrumentales del proyecto de ley, que conforman una estrategia de acción específica donde sus ideas principales no necesariamente se gestan dentro del Documento "Plan".

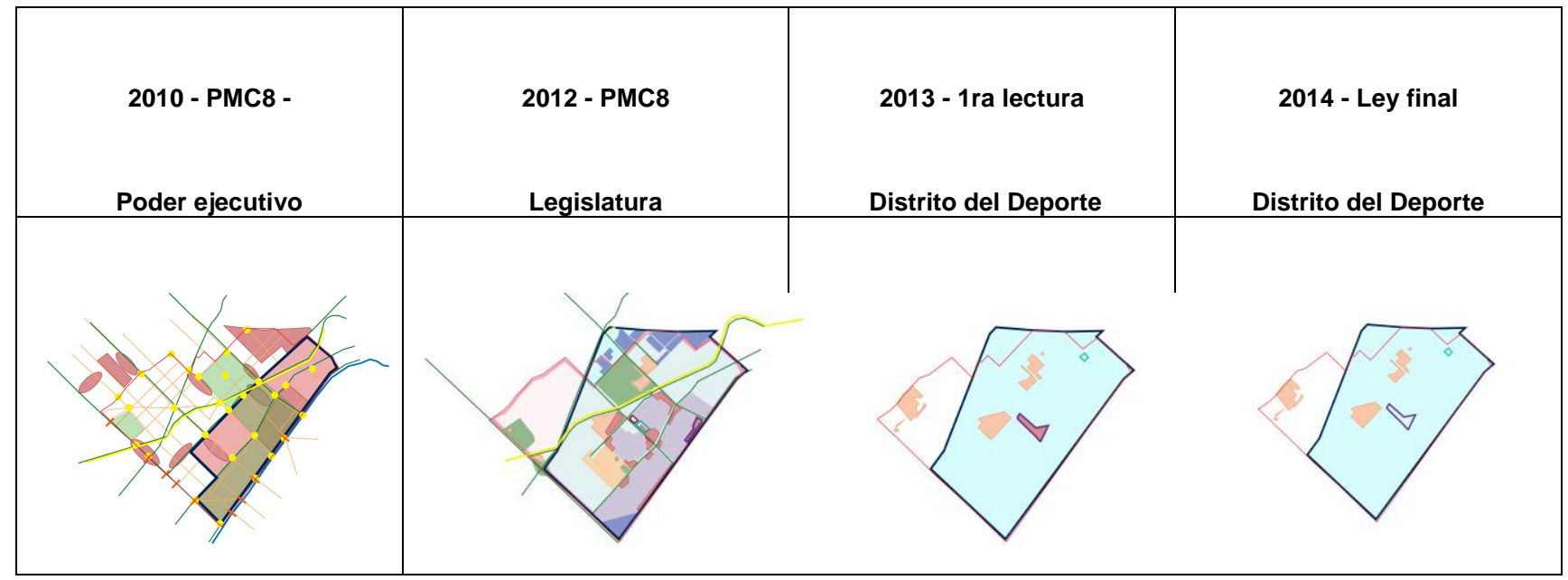

Revisando la secuencia del Plan dentro del proceso legislativo, se observa que el rechazo de la oposición en la legislatura, y de diferentes colectivos sociales respecto de la estrategia propuesta por los legisladores oficialistas, provocaron un cambio en la estrategia en la búsqueda de la legalización de este plan. Sin embargo, mas allá de los argumentos explicitados en el Despacho de Minoría, las razones por las cuales se resuelve eliminar la mayoría de los artículos del texto, y el propio nombre del la ley "Plan Maestro Comuna 8" para el pase a votación en el recinto, no quedan plasmadas en ninguno de los documentos estudiados ${ }^{19}$.

Mientras tanto, el segundo conjunto de textos (ley ley aprobada el primera lectura y la versión final), representan la dicotomía entre la legitimidad y de legalidad del Propio Plan Maestro, ya que la decisión de acotar su alcance, eliminando la mayor parte de las estrategias territoriales propuestas para lograr su aprobación legal, prioriza la legalización y aprobación de determinados instrumentos, como el Distrito del deporte, a cambio de la pérdida del resto del bagaje instrumental propuesto. De esta forma, podría plantearse que, si bien el plan "se achica" para poder ser legal, instala las bases para la aprobación de los demás instrumentos propuestos, que reaparecen de manera autónoma más adelante en el tiempo, con sus propios proyectos de ley: la urbanización de la villa 20, la puesta en valor del autódromo y la concesión de nuevo suelo, la ley de Distrito Villa Olímpica, entre otros.

\footnotetext{
18 disponible en: http://www.minutouno.com/notas/347057-el-pro-aprobo-su-plan-maestro-la-comuna-8

${ }^{19}$ El diario Pagina 12 se refiere a este hecho como la aprobación de "una versión recortada" del PMC8, y explica que la versión original incluía la venta de 70 hectáreas en la zona. Extraído del artículo: "una ley con polémica" - 6 de diciembre de 2013 . disponible en https://www.pagina12.com.ar/diario/sociedad/subnotas/235123-65989-2013-12-06.html
} 
Se desprende de este análisis que durante el proceso realizado dentro de la Legislatura, se produce un giro en el cual la ley pasa a ubicarse dentro de la órbita del Ministerio de Desarrollo Económico, y se apunta a reducción de la figura del Ministerio de Desarrollo Urbano y sus respectivos dispositivos de control de los cambios en materia de normativa urbana en el proceso (como el consejo del Plan Urbano Ambiental COPUA, entre otros ejemplos). Esta estrategia posibilitó también que la aprobación final de la ley se realizara sin necesidad de contar con los 40 votos (fue aprobada con 31). El proceso también fue afectado por las elecciones legislativas de 2013, en las cuales se renovó parte de los legisladores. La aprobación en primera lectura de la ley en diciembre de ese año constituye la última sesión realizada por los diputados salientes.

El compilado de artículos que finalmente fueron aprobados en el texto de la ley, representa las pujas de poderes de los actores sociales implicados en este proceso, donde estos poseen mayor o menor peso específico y capacidad para instalar sus necesidades en la agenda política. Por citar algunos ejemplos:

- El poder ejecutivo del GCBA, que expande sus políticas de generación de distritos temáticos, y la batería de instrumentos de beneficios fiscales.

- Los legisladores oficialistas y de los demás partidos, que debaten para plasmar en los textos de las leyes, las estrategias impulsadas desde cada uno de ellos.

- Otras reparticiones del Gobierno de la Ciudad que se manifiestan a favor o en contra del avance del proyecto, o se disputan el control de algunos instrumentos, como en el caso del IVC y la CBAS.SE. en relación a la gestión de las viviendas de la Villa Olímpica.

- Las organizaciones villeras que buscan instalan sus barrios como prioritarios en la ejecución de los procesos de urbanización.

- Las instituciones deportivas que disponen actualmente de predios públicos para la realización de sus actividades.

- Las empresas constructoras, que participan de las licitaciones públicas para las construcción de edificios en predios anteriormente vedados por la normativa, ampliándose así los espacios para la generación de productos inmobiliarios, como en el caso de la Villa Olímpica.

Independientemente de los alcances concretos, la secuencia que se genera desde la elaboración del documento "plan" del ejecutivo, hasta la aprobación final de la ley, pasando por la versión de 2012, la de 2013, la audiencia pública y la ley aprobada en 2014, instala el concepto de Plan Comunal en los medios de comunicación y en los debates a nivel de gestión, políticos y académicos. La estrategia entonces de la elaboración de un Plan de Comuna puede considerarse valiosa, mas allá de las criticas especificas de este caso, en la medida que pudo dar impulso al despliegue de políticas publicas, en un sector postergado de la ciudad.

Es necesario entonces, como fases indispensables del propio Plan, replantear la integralidad de sus metas, reconstruyendo sus objetivos principales; construir y atravesar las instancias de monitoreo y actualización de este, a fin de verificar hacia donde se está conduciendo la comuna; y revisar si los instrumentos finalmente puestos en práctica se condicen con sus metas en materia de planificación urbana.

\section{Bibliografía}

Documentos base analizados:

- "Informe diagnostico para la elaboración del Plan de Comuna 8". Secretaria de Planeamiento, ministerio de Desarrollo Urbano, Gobierno de la Ciudad de Buenos Aires, año 2011. Disponible en http://www.buenosaires.gob.ar/sites/gcaba/files/planc8.pdf

- Proyecto de ley "Plan Maestro Comuna 8" - año 2012 - 3257-D" - Legislatura de la Ciudad Autónoma de Buenos Aires. Disponible en $\mathrm{http}: / /$ observatoriociudad.org/?s=biblioteca_externa_a\&n=16 
- Documento: Despacho en Mayoría y en Minoría, Legislatura de la Ciudad de Buenos Aires.

- Proyecto de ley "Promoción de las Actividades de la Producción e Industria Deportiva en la Ciudad Autónoma de Buenos Aires" - diciembre 2013 - Disponible en el número 4330 del Boletín oficial http://boletinoficial.buenosaires.gov.ar/

- Ley 5235 "Promoción de las Actividades de la Producción e Industria Deportiva en la Ciudad Autónoma de Buenos Aires" - diciembre 2014. Disponible en el número 4628 del Boletín oficial. http://boletinoficial.buenosaires.gov.ar

Artículos periodísticos consultados:

año 2012

- $\quad$ Diario Z:" Plan Maestro Comuna 8: Cirugía mayor de espacios verdes". Publicado el 30 de noviembre - disponible en http://www.diarioz.com.ar/\#!/nota/plan-maestro-comuna-8-cirugia-mayorde-espacios-verdes-26374/

- Diario La Nación: "El Pacto PRO - K sigue con la venta de tierras públicas y un barrio de lujo". Publicado el 13 de noviembre - disponible en http://www.lanacion.com.ar/1526014-el-pacto-pro-ksigue-con-la-vent

- blog - Republica de Lugano: "Crean el área Reserva ecológica en la zona del Lago de

- Lugano" - Publicado el 30 de noviembre. disponible en http://republicadelugano.blogspot.com.ar/2012_11_01_archive.html

Año 2013

- Noticiario Sur: "La legislatura voto el Plan de la Comuna 8". Publicado en diciembre 2013. Disponible en http://www.noticiariosur.com.ar/titulos/destacados/la-legislatura-voto-el-plan-de-lacomuna-8

- Diario Página 12: " Una ley con polémica". Publicado en diciembre 2013. Disponible en https://www.pagina12.com.ar/diario/sociedad/subnotas/235123-65989-2013-12-06.html

Año 2014

- La izquierda Diario: "Desalojos, un plan para la zona sur" .Publicado en agosto de 2014. Disponible en: http://www.laizquierdadiario.com/Desalojos-un-plan-para-la-zona-sur

- La Tribuna: " El Masterplan de la Comuna 8 y la mercantilización de las villas". Publicado en junio 2014. Disponible en http://latribuna69.org/el-qmaster-planq-de-la-comuna-8-y-la-mercantilizacionde-las-villas/

- Minuto Uno: "EI PRO aprobó su Plan Maestro para la Comuna 8". Publicado en diciembre 2014. Disponible en http://www.minutouno.com/notas/347057-el-pro-aprobo-su-plan-maestro-la-comuna-8

- PuraCiudad: "La ciudad crea el Distrito del Deporte en la Comuna 8". Publicado en Diciembre 2014. Disponible en http://www.puraciudad.com.ar/la-ciudad-crea-el-distrito-del-deporte-en-la-comuna-8/

- Síntesis porteña: "fue aprobado por legislatura". Publicado en diciembre 2014. disponible en http://www.sintesisporteña.com.ar/amplia-nota.php?id_n=26824

Autores de referencia en el marco de la tesis:

- ANDER EGG, Ezequiel (2007) “Introducción a la planificación Estratégica”, Ed. Lumen - Hvmanitas, Buenos Aires - Mexico.

- $\quad$ BRENNER, N. (2003) " La formación de la ciudad global y el re-escalamiento del espacio del Estado en la Europa Occidental post-fordista". EURE (Santiago) [online], vol.29. 
- CORTI, Marcelo: "El plan estratégico Territorial y la construcción de la Argentina deseada, la búsqueda de consensos para el despliegue territorial de la inversión pública", en Café de las ciudades № 66, 2008.

- COSACOV, Natalia y otros: "Barrios al sur: Villa Lugano, Villa Riachuelo, Mataderos, Parque Patricios y Villa Soldati a través del tiempo" - instituto de investigaciones Gino Germani - Fac. de ciencias sociales - UBA.

- DI VIRGILIO, Mercedes y otros: "La ciudad al sur de la ciudad: historia socio urbana de los barrios Villa Lugano y Villa Riachuelo", Bogotá, 2010.

- ESTEVEZ, Alejandro, ESPER, Susana (2008): "Revisitando el modelo secuencial de políticas públicas", Instituto AFIP.

- GARCÍA, R. (2006) "Sistemas complejos. Conceptos, método y fundamentación epistemológica de la investigación interdisciplinaria", Ed Gedisa, Barcelona.

- GIDDENS, A (1982): "Hermenéutica y teórica social", en profiles and critics in social theory, UCP, Los Angeles (traducción).

- HERZER, DI VIRGILIO, MERLINSKY, RODRÍGUEZ: "La cuestión urbana interrogada", Ed. Café de las Ciudades, Agosto 2011

- JAJAMOVICH, Guillermo: "Apuntes para una crítica al Modelo Territorial de Buenos Aires", en Café de Las ciudades № 118, 2012.

- JAUREGUI, Jorge M., "Estrategias de Articulación urbana", Ed. Nobuko, Buenos Aires, 2012.

- MATUS, Carlos (1972). "Estrategia y Plan. Santiago de Chile". Editorial Universitaria.

- MORO, J (2000): "Problemas de agenda y problemas de investigación", en Escolar, C. (compiladora):"topografías de la investigación", Ed. EUDEBA.

- NOVICK, Alicia y CARIDE, Horacio: "Ciudad versus Área metropolitana: notas para una historia del gran Buenos Aires", en Documents de discussion № 37, Unesco.

- NOVICK, Alicia: "Plan. Planes en Buenos Aires". En LIERNUR, JF y ALIATA, F (compiladores). "Diccionario de Arquitectura en la Argentina. Estilos, obras, biografías, instituciones, ciudades". Buenos Aires. Clarín Arquitectura, 2004.

- PETRELLI, Hernán, y otros (2015): "Las capacidades estatales de intervención territorial en Latinoamérica". Instituto Provincial de la Administración Pública, Gobierno de la Provincia de Buenos Aires.

- PÍREZ, P. (1995): "Actores sociales y gestión de la ciudad"- CONICET/CEA-UBA - Publicado en CIUDADES 28, 1995, RNIU, México.

- REESE, Eduardo: "No hay políticas para regular el suelo", Diario Página 12, 2013.

- SZAJNBERG, D; y otros (2010) "Balance de las estrategias de Intervención urbanística en los albores del siglo XXI". Scripta Nova. [En línea]. Barcelona: Universidad de Barcelona, vol. XIV, no 331 (24). 